\title{
Separation of Fischer-Tropsch Wax from Catalyst by Supercritical Extraction
}

\author{
Quarterly Report \\ October 1 - December 31, 1997
}

\author{
By \\ Patrick C. Joyce \\ Mark C. Thies
}

Work Performed Under Contract No.: DE-FG22-94PC94219

\author{
For \\ U.S. Department of Energy \\ Office of Fossil Energy \\ Federal Energy Technology Center \\ P.O. Box 880 \\ Morgantown, West Virginia 26507-0880 \\ By \\ Clemson University \\ Department of Chemical Engineering \\ 123 Earle Hall \\ Clemson, South Carolina 29634-0909
}




\section{Disclaimer}

This report was prepared as an account of work sponsored by an agency of the United States Government. Neither the United States Government nor any agency thereof, nor any of their employees, makes any warranty, express or implied, or assumes any legal liability or responsibility for the accuracy, completeness, or usefulness of any information, apparatus, product, or process disclosed, or represents that its use would not infringe privately owned rights. Reference herein to any specific commercial product, process, or service by trade

name, trademark, manufacturer, or otherwise does not necessarily constitute or imply its endorsement, recommendation, or favoring by the United States Government or any agency thereof. The views and opinions of authors expressed herein do not necessarily state or reflect those of the United States Government or any agency thereof. 


\section{Separation of Fischer-Tropsch Wax from Catalyst by Supercritical Extraction}

Report Type: QUARTERLY $\quad$ Reporting Period Start Date: 10/01/1997 End Date: 12/31/1997 Principal Author(s): Patrick C. Joyce and Mark C. Thies

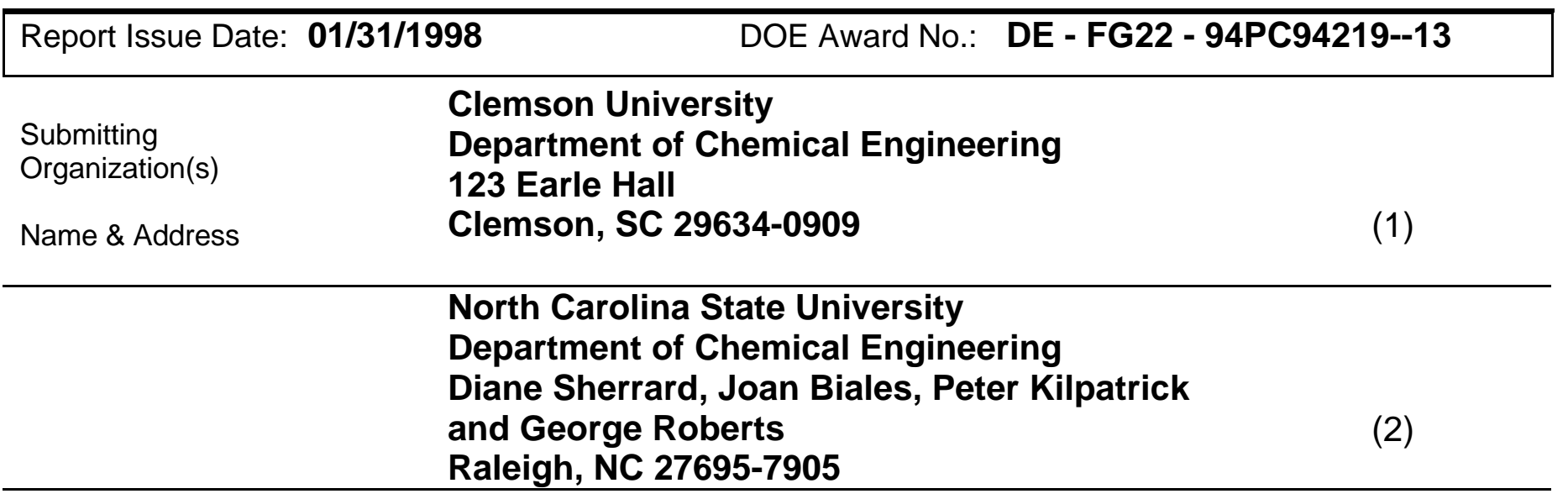

(4) 


\section{Executive Summary}

Although alkanes are the major constituent of a Fischer-Tropsch wax, significant quantities of long-chain olefins can also be found. With the lack of experimental data, the effect of the double-bond functional group on the phase behavior of supercritical fluid solvent/wax systems is uncertain. Therefore, the phase behavior of the system hexane/1hexadecene was measured for comparison with the previously measured system hexane/hexadecane. Vapor and liquid equilibrium compositions and mixture critical points were measured at $198.9,251.5$, and $299.4{ }^{\circ} \mathrm{C}$ at pressures ranging from 7.9 to 40.1 bar. Temperature and pressure measurements for all isotherms are believed to be accurate to better than $\pm 0.2{ }^{\circ} \mathrm{C}$ and \pm 0.14 bar, respectively. Considering all sources of error, the reported liquid- and vapor-phase compositions are believed to be accurate to better than $\pm 3 \%$.

Results indicate that the double bond in a $\mathrm{C}_{16}$ hydrocarbon chain has little effect on the phase behavior. Thus, their presence in Fischer-Tropsch waxes (whose components are generally at least as long as a $\mathrm{C}_{16}$ ) can probably be safely ignored in performing phase equilibrium calculations for our proposed wax extraction process. The greatest observed difference between hexadecane and hexadecene behavior was at high concentrations (i.e., $>50 \mathrm{~mol} \%$ ) of hexadecene in the liquid phase. Additional analytical work will be required to determine whether these differences are real or due to oligomerization of hexadecene at certain conditions.

Even though the critical point for hexadecene had to be estimated, the PengRobinson equation was found to adequately model the system. The AAPD for the vapor phase was $\sim 2 \%$ and for the liquid phase was $\sim 9 \%$. The optimized binary interaction parameters were $0.00 \pm 0.03$. 


\section{Technical Objectives}

The objective of this research project is to evaluate the potential of supercritical fluid (SCF) extraction for the recovery and fractionation of the wax product from the slurry bubble column (SBC) reactor of the Fischer-Tropsch (F-T) process. The wax, comprised mostly of branched and linear alkanes with a broad molecular weight distribution up to $\mathrm{C}_{100}$, will be extracted with a hydrocarbon solvent that has a critical temperature near the operating temperature of the SBC reactor, i.e., $200-300{ }^{\circ} \mathrm{C}$. Initial work is being performed using n-hexane as the solvent.

The success of the project depends on two factors. First, the supercritical solvent must be able to dissolve the F-T wax; furthermore, this must be accomplished at conditions that do not entrain the solid catalyst. Second, the extraction must be controlled so as not to favor the removal of the low molecular weight wax compounds. That is, a constant carbon-number distribution in the wax slurry must be maintained at steady-state column operation. Three major tasks are being undertaken to evaluate our proposed SCF extraction process. Task 1: Equilibrium solubility measurements for model F-T wax components in supercritical fluids at conditions representative of those in a SBC reactor. Task 2: Thermodynamic modeling of the measured VLE data for extending our results to real wax systems. Task 3: Process design studies of our proposed process. Additional details of the task structure are given below.

\section{Task 1: Equilibrium Solubility Measurements}

a. apparatus modification and construction.

b. experimental measurements of selected model systems.

c. design and construction of new apparatus for measuring VLE of $\mathrm{C}_{36}+$ alkanes with hexane.

\section{Task 2: Thermodynamic Modeling}

a. modeling VLE data using cubic equations of state.

b. examination of theoretically based models, including the SAFT equation.

\section{Task 3: Process Design Studies}

a. process configuration studies using the ASPEN PLUS simulation package. 


\section{Detailed Description of Technical Progress}

\section{Task 1a. Apparatus Modification and Construction}

This task has been completed.

Task 1c. Design and Construction of New Apparatus

No effort planned for this quarter.

Task 1b. Experimental Measurements for n-Hexane/1-Hexadecene System

Vapor-liquid equilibrium experiments for the n-hexane/1-hexadecene system have been completed. Measured compositions and corresponding pressures for this binary at 198.9, 251.5, and $299.4^{\circ} \mathrm{C}$ are given in Table I and are depicted on a pressurecomposition diagram in Figure 1. Mixture critical pressures and compositions are also reported at the two higher temperatures. For clarity, the vapor-phase compositions of the $198.9{ }^{\circ} \mathrm{C}$ isotherm are plotted separately in Figure 2. Oligomerization of the hexadecene was found at $299.4{ }^{\circ} \mathrm{C}$ (about 0.5 wt \% of a $\sim \mathrm{C}_{30}$ hydrocarbon was detected in some of the equilibrium samples). Thus, equilibrium measurements were not attempted at $350{ }^{\circ} \mathrm{C}$ because of the concern over even higher oligomerization levels, which would prevent the measurement of good-quality equilibrium data.

For the liquid phase, the three samples collected at a given temperature and pressure were typically reproducible to better than $\pm 1.0 \%$ deviation in the minor component. For the vapor phase, the samples were always reproducible to better than $\pm 2 \%$ in the minor component hexadecene. Temperature and pressure uncertainties for a given isotherm were always less than $\pm 0.2^{\circ} \mathrm{C}$ and \pm 0.14 bar, respectively. Considering all sources of error, the reported liquid- and vapor-phase compositions are believed to be accurate to $\pm 3 \%$.

The results for the hexane/hexadecene system were compared to the hexane/hexadecane system to examine the effect of the double bond on the phase behavior of the $\mathrm{C}_{16}$ hydrocarbon chain. Figure 3 shows a pressure-temperature diagram 
Table I. Vapor-liquid equilibrium properties for the n-hexane/1-hexadecene system.

\begin{tabular}{|c|c|c|c|c|c|}
\hline \multirow[b]{2}{*}{ press., bar } & \multicolumn{2}{|c|}{ mole fraction 1-hexadecene } & \multirow[b]{2}{*}{ press., bar } & \multicolumn{2}{|c|}{ mole fraction 1-hexadecene } \\
\hline & liquid & vapor & & liquid & vapor \\
\hline & $\mathrm{T}=198.9^{\circ} \mathrm{C}$ & & & $\mathrm{T}=299.4$ & \\
\hline 7.91 & 0.454 & 0.0115 & 7.84 & 0.746 & 0.200 \\
\hline 9.63 & 0.362 & 0.00890 & 13.08 & 0.623 & 0.129 \\
\hline 11.36 & 0.274 & 0.00683 & 18.25 & 0.521 & 0.101 \\
\hline 13.08 & 0.194 & 0.00512 & 23.42 & 0.431 & 0.0869 \\
\hline 14.80 & 0.119 & 0.00340 & 28.59 & 0.341 & 0.0809 \\
\hline 16.53 & 0.0487 & 0.00160 & 33.76 & 0.262 & 0.0820 \\
\hline \multirow[t]{3}{*}{17.42} & 0.0206 & 0.000518 & 38.93 & 0.179 & 0.0992 \\
\hline & & & $40.07^{\mathrm{a}}$ & 0.135 & 0.135 \\
\hline & $\mathrm{T}=251.5^{\circ} \mathrm{C}$ & & & & \\
\hline 7.91 & 0.637 & 0.0647 & & & \\
\hline 13.60 & 0.482 & 0.0410 & & & \\
\hline 18.25 & 0.354 & 0.0308 & & & \\
\hline 21.70 & 0.275 & 0.0272 & & & \\
\hline 25.14 & 0.198 & 0.0241 & & & \\
\hline 28.59 & 0.128 & 0.0219 & & & \\
\hline 32.04 & 0.067 & 0.0210 & & & \\
\hline $33.76^{\mathrm{a}}$ & 0.0326 & 0.0326 & & & \\
\hline
\end{tabular}

of the critical-locus curves for both systems; the lines are simply smooth curves that connect the measured and pure-component critical points. The critical point of pure 1hexadecene was estimated by extrapolation of a correlation developed by Teja and coworkers [1] for 1-alkenes up to $\mathrm{C}_{12}$, and the critical point of hexadecane is available in the literature [2,3]. As can be seen in Figure 3, the critical-locus curves for the two binaries are quite similar.

Vapor-phase compositions for the two binaries are compared in Figure 4. Hexadecene solubilities in the vapor phase at $199{ }^{\circ} \mathrm{C}$ are consistently $7-10 \%$ higher than those for hexadecane, but for the two higher-temperature isotherms essentially no differences are observed. To verify that the differences observed between the two systems at $199^{\circ} \mathrm{C}$ were not simply the result of data scatter, two compositions for the hexane/hexadecane system were re-measured. As can be seen in Table II below, the "repeats" were virtually identical to those previously made. We therefore conclude that the measured differences are real. The fact that hexadecene has a vapor pressure approximately $7 \%$ higher than hexadecane at $200{ }^{\circ} \mathrm{C}$ is the most likely explanation for the results observed in Figure 4a. At the supercritical temperatures (Figure 4b), the solvent power has a much greater impact on solute solubility than vapor pressure. 
Table II. Reproducibility check for the hexane/hexadecane system at $199.2{ }^{\circ} \mathrm{C}$.

\begin{tabular}{ccccccc}
\hline Pressure & \multicolumn{2}{c}{$9 / 18 / 96$ results } & \multicolumn{2}{c}{$11 / 25 / 97$ repeats } & \multicolumn{2}{c}{ Deviation } \\
(bar) & $\mathrm{x}$ & $\mathrm{y}$ & $\mathrm{x}$ & $\mathrm{y}$ & $\mathrm{x}$ & $\mathrm{y}$ \\
\hline 7.91 & 0.462 & 0.0107 & 0.457 & 0.0107 & $-1.1 \%$ & $0.0 \%$ \\
9.63 & 0.363 & 0.00818 & 0.361 & 0.00827 & $-0.6 \%$ & $1.1 \%$
\end{tabular}

For the liquid-phase compositions (Figure 5), essentially no deviation was observed between the two binary systems at $200{ }^{\circ} \mathrm{C}$. At $250{ }^{\circ} \mathrm{C}$, no deviation is observed at higher pressures where the hexadecene concentration is low, but at lower pressures (e.g., $\sim 8$ bar) where the hexadecene concentration exceeds $50 \mathrm{~mol} \%$ the deviations become significant. At $300{ }^{\circ} \mathrm{C}$, the highest deviations are observed and also become observable at hexadecene concentrations above $50 \mathrm{~mol} \%$. It is of concern that the deviations in Figure 5 are consistent with oligomerization of the hexadecene: they are the worst at the highest temperatures and the greatest hexadecene concentrations.

Furthermore, the direction of the deviations (i.e., less hexadecene is present in the liquid phase than would be expected) is also consistent with oligomerization. However, as stated above only $0.5 \mathrm{wt} \%$ of a dimer was seen at $300{ }^{\circ} \mathrm{C}$, and no dimers were observed at $250{ }^{\circ} \mathrm{C}$. This degree of oligomerization would be essentially undetectable within the reported accuracies of the experimental data. Additional analyses will be performed on the collected liquid samples in the future to determine more precisely to what extent oligomerization may be occurring.

\section{Task 2a. Modeling VLE Data with Cubic Equations of State}

The experimental data for the hexane/1-hexadecene binary were modeled using the Peng-Robinson equation of state (P-R). Table III shows the pure-component parameters that were used. As mentioned above, the critical temperature and pressure were estimated by the method of Gude et al. [1]. The acentric factor was regressed from vapor pressure data [4] using the method described by Hutchenson [5]. 
Table III. Estimated 1-hexadecene properties.

\begin{tabular}{c|ccc} 
& $\mathrm{T}_{\mathrm{c}}(\mathrm{K})$ & $\mathrm{P}_{\mathrm{c}}(\mathrm{bar})$ & $\omega$ \\
\hline 1-hexadecene & 721.5 & 15.2 & 0.767
\end{tabular}

Table IV shows the optimized binary interaction parameters and the average absolute percent error between the calculated and measured compositions for P-R. Figures 6 and 7 show the fit of P-R to the experimental data. Calculated and experimental data are shown in Figure 6 for the vapor phase, and in Figure 7 for the liquid phase for the two isotherms above the critical point of hexane. As can be seen in Figure 6 and in Table IV, P-R does an excellent job predicting the compositions in the vapor phase. In the liquid phase, compositions near the mixture critical point are poorly represented, as are the mixture critical points themselves. It is interesting to note that P-R predicts that there should be more hexadecene in the liquid phase at hexadecene concentrations $>50 \mathrm{~mol} \%$, which also suggests the presence of oligomerization.

Table IV. Optimized binary interaction parameters for PR and the resulting AAPD's.

\begin{tabular}{cccc}
\hline Temperature $\left({ }^{\circ} \mathrm{C}\right)$ & Optimized $\mathrm{k}_{\mathrm{ij}}$ & AAPD in $\mathrm{a}^{\mathrm{a}}$ & AAPD in $\mathrm{y}$ \\
\hline 198.9 & 0.00 & 9.4 & 2.9 \\
251.5 & 0.00 & 8.5 & 1.9 \\
299.4 & -0.03 & 8.7 & 1.5 \\
${ }^{\mathrm{a}}$ AAPD $=\sum_{\mathrm{i}}\left|\frac{\left(\mathrm{x}_{\mathrm{i}}[\exp ]-\mathrm{x}_{\mathrm{i}} \text { [calc] }\right]}{\mathrm{x}_{\mathrm{i}}[\mathrm{exp}]}\right| \times 100 \%$ & &
\end{tabular}

Task 2b. Examination of Theoretically Based Equations of State

No effort planned this quarter.

Task 3a. Process Configuration Studies Using the ASPEN PLUS Simulation Package

No report planned for this quarter.

\section{Plans for Next Quarter}

The oligomerization issue with hexadecene will be resolved, and phase equilibrium experiments for the system hexane/hexatriacontane $\left(\mathrm{C}_{36}\right)$ (the longest alkane to be measured with the existing apparatus) will be made. 


\section{References}

1. Gude, M. T., Rosenthal, D. J., and Teja, A. S., "The Critical Properties of 1-Alkenes from 1-Pentene to 1-Dodecene," Fluid Phase Equil. 70, 55-64 (1991).

2. Reid, R. C., Prausnitz, J. M., and Poling B. E., The Properties of Liquids and Gases, 4th Ed. McGraw-Hill: New York (1987).

3. Ambrose, D., and Tsonopoulos, C., "Vapor-Liquid Critical Properties of Elements and Compounds. 2. Normal Alkanes," J. Chem. Eng. Data 40, 531-546 (1995).

4. Camin, D. L., Forziati, A. F., and Rossini, F. D., "Physical Properties of nHexadecane, n-Decylcyclopentane, n-Decylcyclohexane, 1-Hexadecene, and nDecylbenzene," J. Phys Chem. 58, 440-442 (1954)

5. Hutchenson, K. W., "Fractionation of Petroleum Pitch by Supercritical Fluid Extraction: Experimental Phase Behavior and Thermodynamic Modeling," Ph. D. Dissertation, Clemson University, Clemson, SC (1990). 


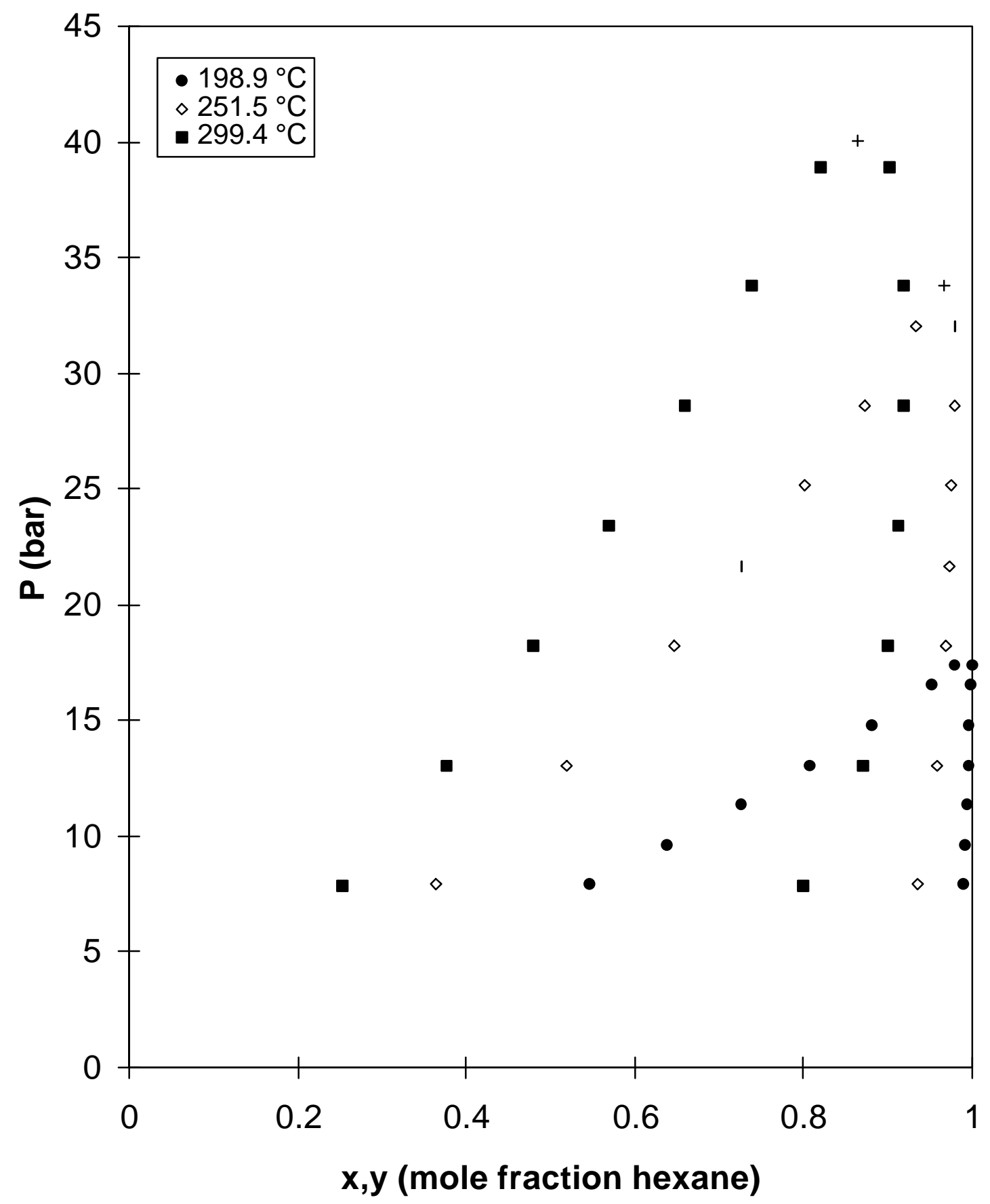

Figure 1. Pressure vs composition diagram for the hexane/1-hexadecene system at 198.9 ${ }^{\circ} \mathrm{C}, 251.5^{\circ} \mathrm{C}$, and $299.4{ }^{\circ} \mathrm{C}$. The + are the mixture critical points. 


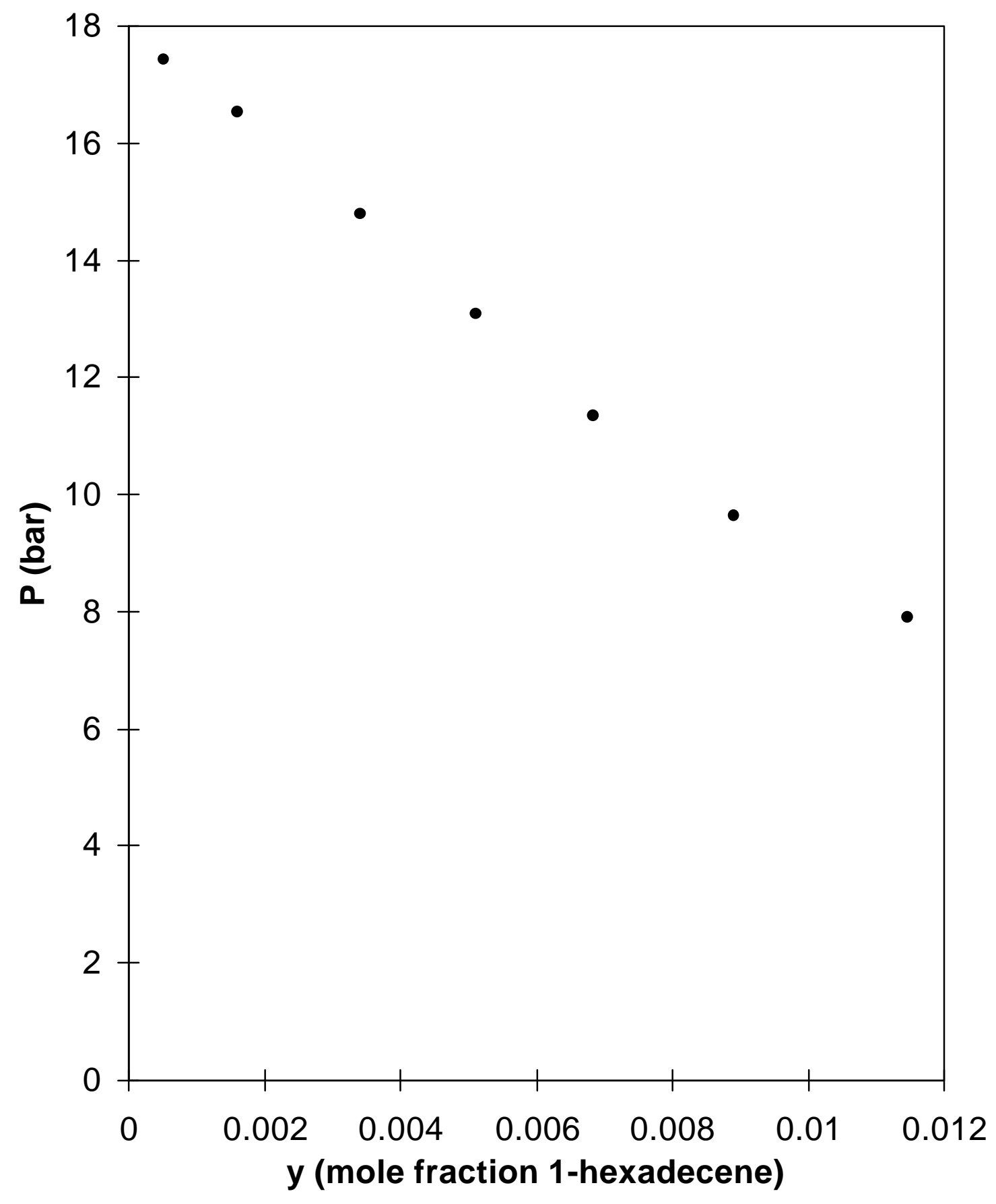

Figure 2. Vapor-phase compositions for the hexane/1-hexadecene system at $198.9{ }^{\circ} \mathrm{C}$. 


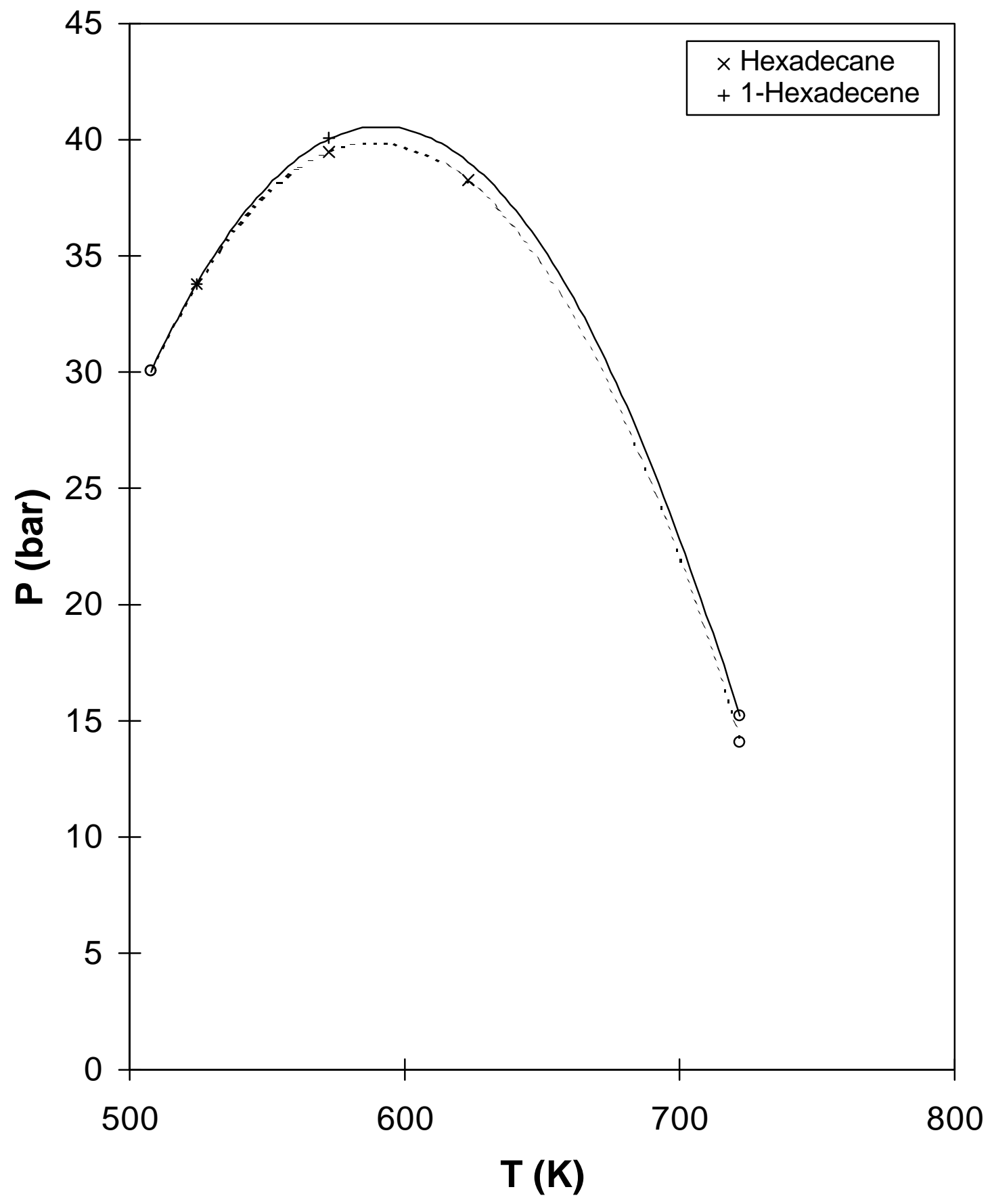

Figure 3. Critical-locus curves for binary mixtures of hexane with hexadecane and 1hexadecene. The open circles represent the pure component critical points. 

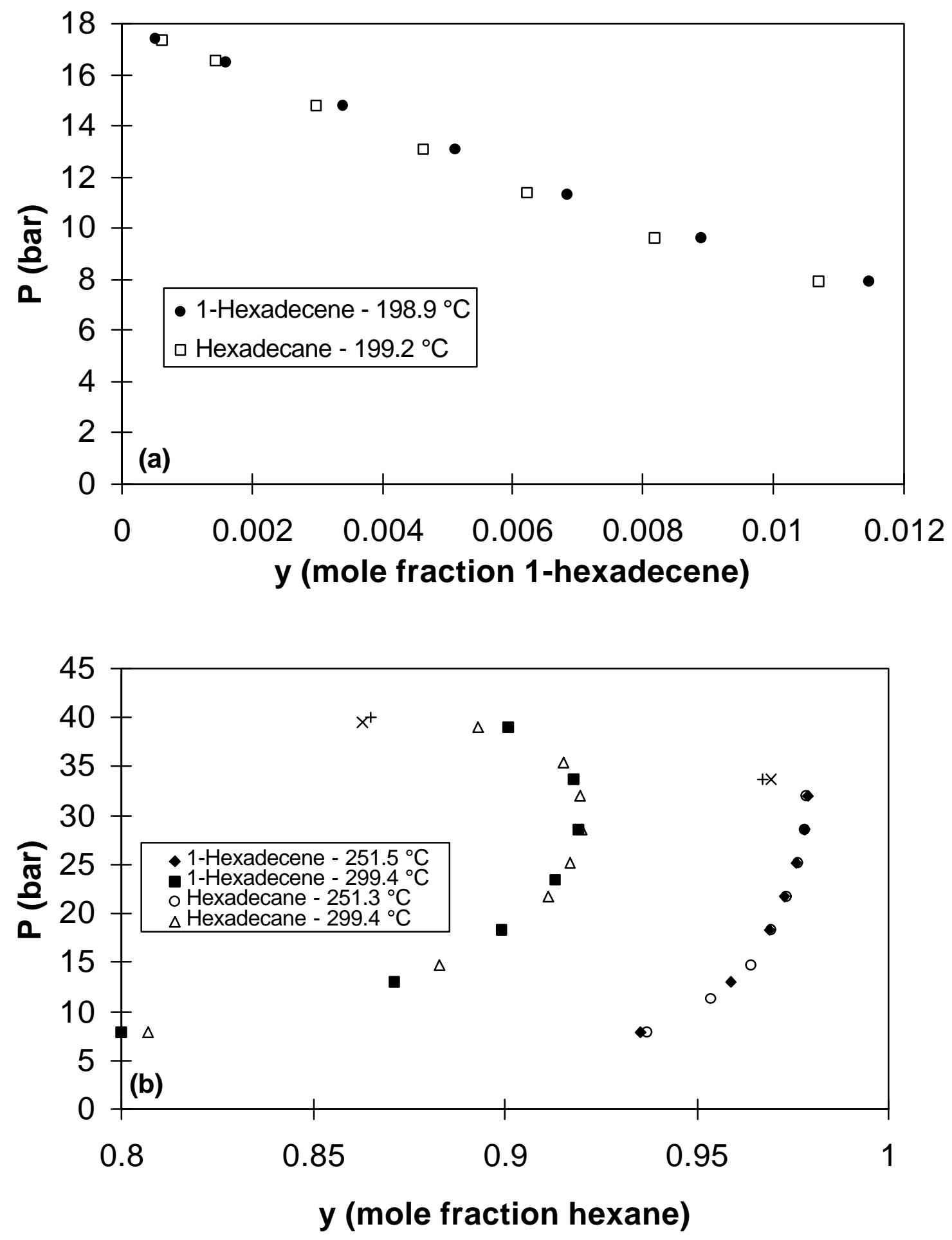

Figure 4. Comparison of the vapor-phase compositions for the hexane/hexadecane and hexane/1-hexadecene systems at (a) subcritical and (b) supercritical temperatures. The + are the mixture critical points for hexane/1-hexadecene, and the $\mathrm{x}$ are the mixture critical points for hexane/hexadecane. 


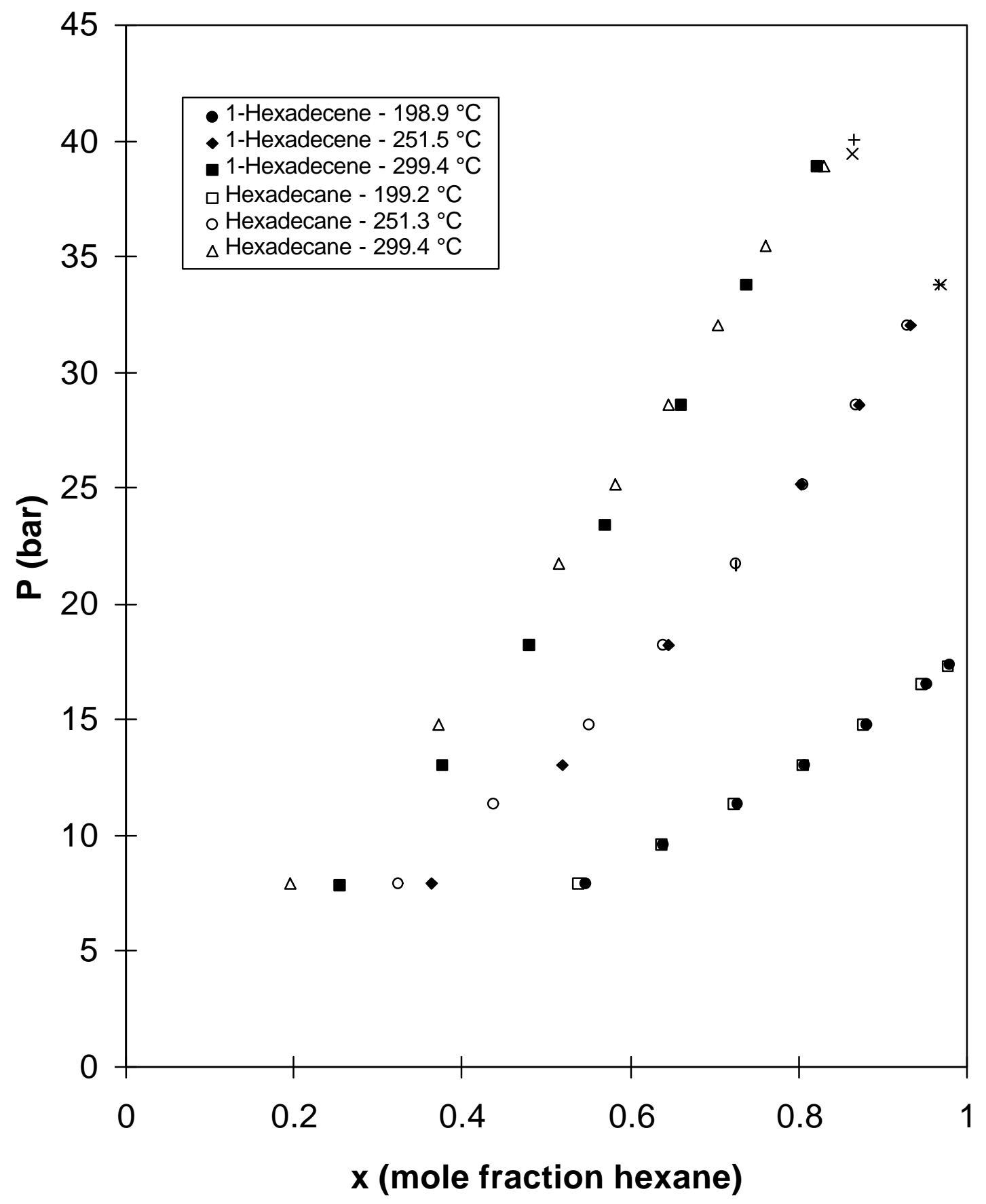

Figure 5. Comparison of the liquid-phase compositions for the hexane/hexadecane and hexane/1-hexadecene systems. The + are the mixture critical points for hexane/1hexadecene, and the $\mathrm{x}$ are the mixture critical points for hexane/hexadecane. 


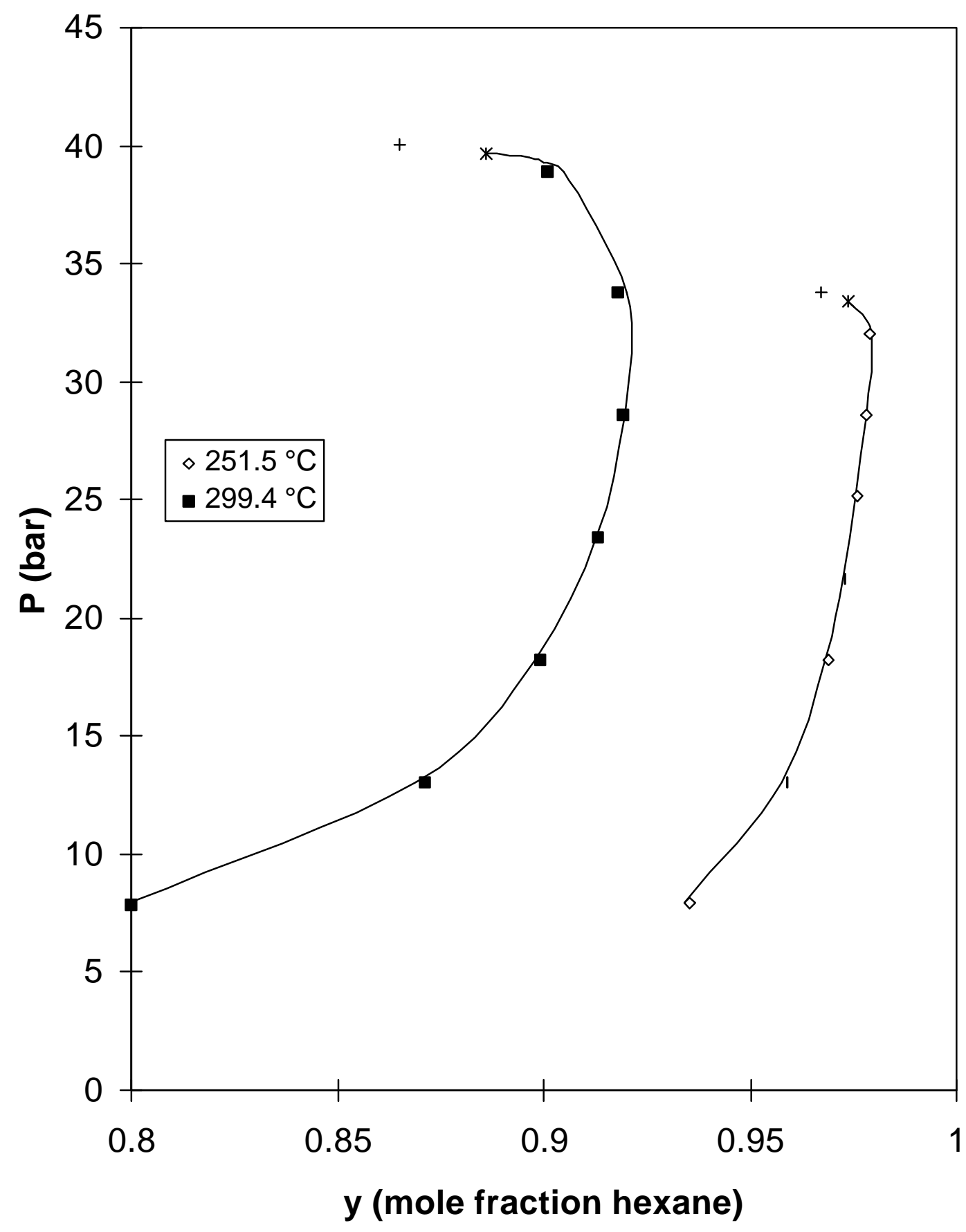

Figure 6. Comparison of Peng-Robinson calculations with experimental data for the vapor-phase compositions. The + are the measured mixture critical points, and the $*$ are the P-R calculated mixture critical points. 


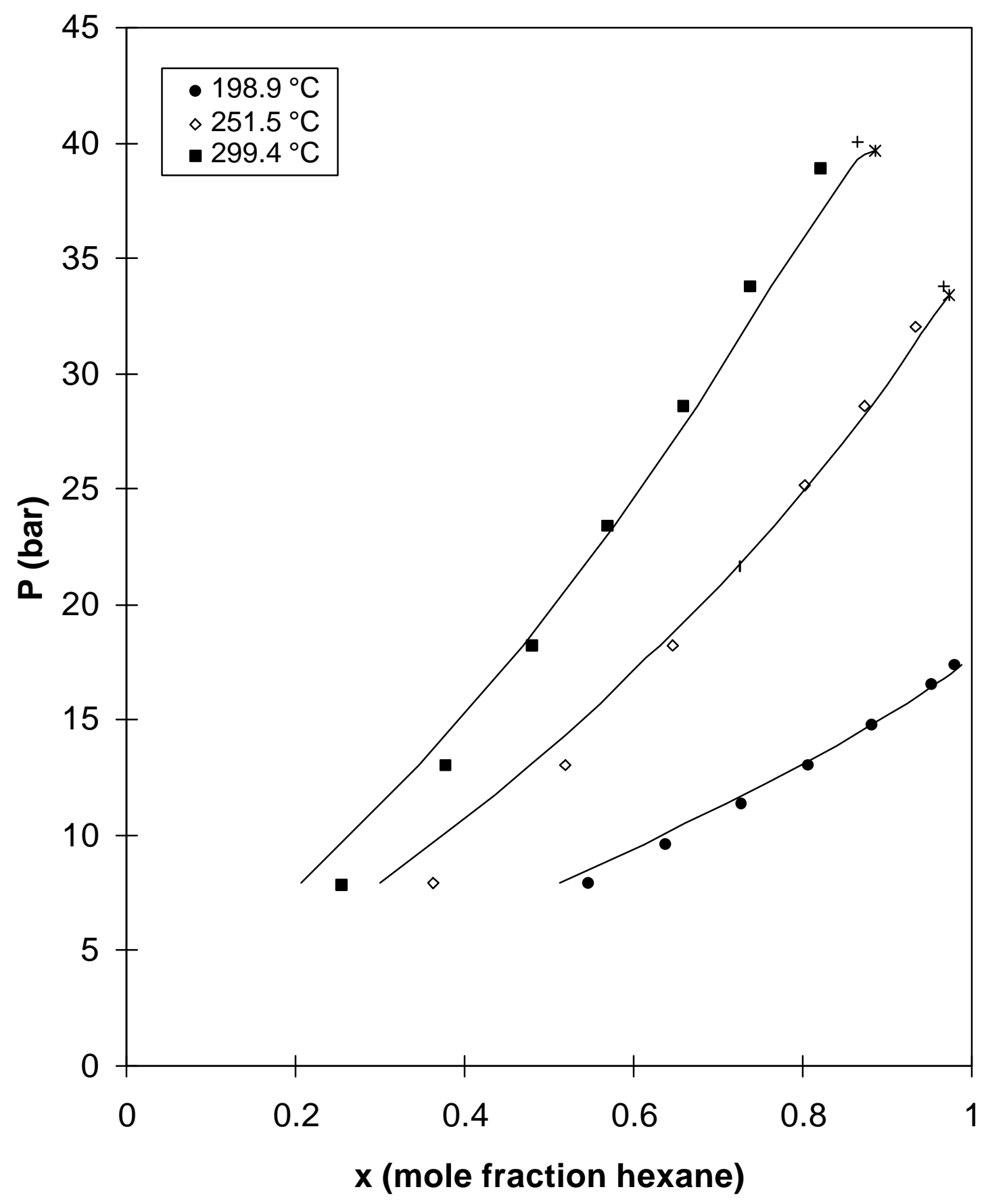

Figure 7. Comparison of Peng-Robinson calculations with experimental data for the liquid-phase compositions. The + are the measured mixture critical points, and the $*$ are the P-R calculated mixture critical points. 